\title{
Polymerase chain reaction in the diagnosis of bacterial endophthalmitis
}

\author{
K L Therese, A R Anand, H N Madhavan
}

\begin{abstract}
Background-Microbiological investigations of vitreous fluid (VF) and aqueous humour (AH) specimens have often failed to detect the infecting agent in infectious endophthalmitis, resulting in a clinical dilemma regarding therapy. In this study, the polymerase chain reaction (PCR) was evaluated in the diagnosis of bacterial and Propionibacterium acnes endophthalmitis.

Methods-58 intraocular specimens (30 VF and $28 \mathrm{AH})$ from 55 cases of endophthalmitis and 20 specimens (14 VF and 6 AH) as controls from non-infective disorders were processed for microbiological investigations. Nested PCR directed at the 16S rDNA using universal primers for eubacterial genome was done. PCR for $P$ acnes was performed on specimens microbiologically negative by conventional techniques but eubacterial genome positive.
\end{abstract}

Results-Of the 20 controls from noninfective cases, one (5\%) was positive using eubacterial primers and none with $P$ acnes primers. PCR for eubacterial genome showed $100 \%$ correlation with 20 $(34.5 \%)$ bacteriologically positive specimens. Eubacterial genome, was detected in $17(44.7 \%)$ of 38 bacteriologically negative specimens and nine $(52.9 \%)$ out of the 17 were positive for $P$ acnes genome. Among the 21 eubacterial PCR negative specimens, seven were fungus positive. $B y$ inclusion of PCR, microbiologically positive specimens increased from $46.5 \%$ to $75.8 \%$. PCR on AH was as sensitive as that on VF for the detection of both eubacterial and the $P$ acnes genome.

Conclusion-PCR performed on $\mathrm{AH}$ and $V F$ is a reliable tool for the diagnosis of bacterial and $P$ acnes endophthalmitis particularly in smear and culture negative specimens.

(Br f Ophthalmol 1998;82:1078-1082)

Vision Research

Foundation, Chennai, India

K L Therese

A R Anand

H N Madhavan

Correspondence to: Dr H N Madhavan, Vision Research Foundation, Sankara Nethralaya, 18 College Road, Chennai 600006 , India.

Accepted for publication 17 March 1998

Bacterial endophthalmitis, the most form of vision threatening ocular infection may, follow surgery, trauma, bacterial keratitis, or may be of endogenous origin..$^{1-3}$ Several Gram positive and Gram negative bacteria including anaerobic bacteria cause endophthalmitis. ${ }^{124}$ The value of culture of vitreous fluid $(\mathrm{VF})$ and aqueous humour $(\mathrm{AH})$ specimens in the diagnosis of infectious endophthalmitis is well established, ${ }^{5}{ }^{6}$ but often negative cultures are encountered resulting in a clinical dilemma over the cause of the inflam- mation. A rational approach to the use of antibiotics and steroids necessitates determining whether the inflammation is infectious or sterile. Therefore, in such cases, an aetiological diagnosis is essential.

The new molecular biological technique polymerase chain reaction (PCR) has been evaluated in the diagnosis of several infectious diseases $^{7-9}$ PCR, with universal eubacterial primers, possessing broad specificity for all Gram positive and Gram negative bacteria, has been found useful for detection of eubacterial genome in vitreous aspirates of delayed postoperative endophthalmitis cases in comparison with routine microbiological investigations. PCR, with Propionibacterium acnes primers, was also found to bea useful means of diagnosing $P$ acnes delayed onset postoperative endophthalmitis cases, when conventional bacterial culture was negative. ${ }^{10}$ There are many reports of $P$ acnes causing delayed onset endophthalmitis ${ }^{11} 12$ and this bacterium may act as an adjuvant to promote the host's immune response against lens protein. ${ }^{12}$ Owing to the localised nature of this infection in the capsular bag, ${ }^{12}$ the $\mathrm{AH}$ and $\mathrm{VF}$ might contain too few free bacteria to be detected by culture and so it was felt many of the cases of endophthalmitis that were culture negative could be due to $P$ acnes.

Thus, the objective of this study was to evaluate the usefulness of PCR in the aetiological diagnosis of infectious endophthalmitis and, in particular, $P$ acnes endophthalmitis by applying this technique in our clinical setting in the context of smear and culture negative intraocular specimens. We have also analysed the usefulness of PCR on AH compared with $\mathrm{VF}$ in this condition.

\section{Materials and methods}

CLINICAL SPECIMENS AND PATIENTS

Fifty eight clinical specimens (38 VF and 20 $\mathrm{AH}$ ) were obtained from 55 endophthalmitis cases. Twenty clinical specimens $(14 \mathrm{VF}$ and 6 $\mathrm{AH})$ from non-infective patients undergoing surgery for retinal detachment, vitreous haemorrhage, and diabetic retinopathy were used as control specimens.
COLLECTION OF VA AND AH

Uncontaminated VF was aspirated by syringe connected to the suction port of the vitreous cutter at the beginning of vitrectomy. A sterile disposable needle was fixed to the syringe, the air in it expelled carefully without causing aerosols; the needle was capped with a sterile rubber bung and sent to the laboratory immediately. After application of topical analgesia, 
Table 1 Standard ATCC ${ }^{\star}$ bacterial strains and laboratory bacterial strains used for standardisation of specificity of eubacterial and $P$ acnes primers

\begin{tabular}{|c|c|}
\hline Bacterium & Bacterium \\
\hline $\begin{array}{l}\text { S epidermidis (ATCC12228) } \\
S \text { aureus (ATCC 25293) } \\
\text { E faecalis (ATCC29212) } \\
\text { B subtilis (ATCC6644) } \\
P \text { aeruginosa (ATCC7853) } \\
\text { E coli (ATCC25922) } \\
\text { H influenzae (ATCC } 35056 \text { ) } \\
\text { K pneumoniae (ATCC13880) } \\
\text { Ten laboratory isolates of } P \text { acnes were also included }\end{array}$ & $\begin{array}{l}\text { Paeruginosa (M† 2172/95) } \\
\text { S aureus (M 2631/95) } \\
\text { K pneumoniae (M 3050/95) } \\
\text { E faecalis (M 3279/95) } \\
\text { B megaterium (M 3466/95) } \\
\text { S epidermidis (M 103/96) } \\
\text { Alcaligenes faecalis (M 389/96) } \\
\text { Achromobacter spp (M 846/96) } \\
\text { S pneumoniae (M 536/97) } \\
\text { Flavobacterium spp (M 2911/96) } \\
\text { Cxerosis (M 3072/95) } \\
\text { C kutscheri (M 2946/95) }\end{array}$ \\
\hline
\end{tabular}

*American Type Culture Collection. $+M$ denote the laboratory identification numbers.

AH samples (150-200 $\mu \mathrm{l})$ were collected aseptically in a tuberculin syringe with a 30 gauge needle, and $100 \mu \mathrm{l}$ of the sample were transferred into presterilised microfuge tubes and stored at $-20^{\circ} \mathrm{C}$ for PCR. The rest was used for microbiological investigations.

CONVENTIONAL MICROBIOLOGICAL

INVESTIGATIONS

The specimens ( $\mathrm{VF}$ and $\mathrm{AH}$ ) were processed within 30 minutes after collection for culture of aerobic and anaerobic bacteria (Don Whitley Compact anaerobic work station, Thane, India) and fungus. The standard methods ${ }^{13-15}$ were followed for isolation and identification of both aerobic and anaerobic bacteria and fungus. Cultures for bacteria were incubated up to 10 days and for fungus up to 30 days for growth before they were discarded as culture negative. Cytospin (Shandon, USA) smears of VF and AH were stained by Gram's method for detection of bacteria and $10 \% \mathrm{KOH}-$ calcofluor white wet preparation for detection of fungus.

POLYMERASE CHAIN REACTION

PCR was carried out as described below.

DNA extraction

DNA was extracted from standard strains and laboratory isolates as described by Hykin et $a l .{ }^{10}$ The DNA extraction from samples was done using a modification of the above method. Briefly, $50 \mu \mathrm{l}$ of $\mathrm{VF} / \mathrm{AH}$ was added to $150 \mu \mathrm{l}$ of TE buffer (10 mM TRIS-HCl, pH 8.0, EDTA $1 \mathrm{mM}$ ) containing $8 \mu$ l proteinase $\mathrm{K}(20 \mathrm{mg} / \mathrm{ml})$ and $0.5 \%$ SDS and incubated at $56^{\circ} \mathrm{C}$ for 1 hour. An equal volume of phenol:chloroform:isoamyl alcohol mixture was added and centrifuged at $15600 \mathrm{~g}$ for 5 minutes. The aqueous phase was removed and DNA was precipitated with $3 \mathrm{M}$ sodium acetate $\mathrm{pH} 5.2$ (0.1 volume) and absolute ethanol ( 2 volumes). After 30 minutes at $-20^{\circ} \mathrm{C}$, the precipitated DNA was washed with $70 \%$ ethanol, dried, and reconstituted in $20 \mu \mathrm{l}$ TE buffer and stored at $-20^{\circ} \mathrm{C}$ until use.

Primers

Universal eubacterial primers ${ }^{10}$ which have a broad specificity for Gram positive and Gram negative bacteria were custom synthesised by Bangalore Genie Pvt Ltd, India. The sequence of primers used for the first round of eubacterial nested PCR were U1: 5' TTGGAG
AGTTTGATCCTGGCTC 3' and rU4: 5' GGACTACCAGGGTATCTAA 3' which generated a $766 \mathrm{bp}$ product. Primers for the second round were U2: 5' GGCGTGCTTA ACACATGCAAGTCG 3' and rU3: 5' GCG GCTGGCACGTAGTTAG 3' which generated a $470 \mathrm{bp}$ product after amplification by PCR. Primers specific for $P$ acnes used were for the first round Pa1: 5' AAGGCCCTGCTT TTGTGG 3' and rPa3: 5' ACTCACGCT TCGTCACAG 3' generated a 387 bp product, and primers for the second round were $\mathrm{Pa} 1$ and rPa2: 5' TCCATCCGCAACCGCC GAA 3' which generated a 160 bp product after amplification by PCR.

\section{Prevention of contamination}

To prevent contamination PCR preparation, DNA amplification, and analysis of the amplified product were done in separate laboratories. PCR preparation was performed on a laminar flow work bench with single use aliquots of reagent, and dedicated pipettes. Microfuge tubes and mineral oil aliquots were double sterilised.

\section{PCR using universal eubacterial primers}

A $50 \mu \mathrm{l}$ reaction volume consisted of 1 unit of ampliTaq DNA polymerase (Perkin-Elmer, Cetus, USA), $5 \mu \mathrm{l}$ of $10 \mathrm{X}$ PCR buffer ( 500 $\mathrm{mM}$ potassium chloride, $100 \mathrm{mM}$ TRIS chloride, $15 \mathrm{mM}$ magnesium chloride, gelatin $0.1 \%, \mathrm{pH} 8.3), 0.36 \mu \mathrm{M}$ of each primer, 200 $\mu \mathrm{M}$ of each deoxyribonucleotide triphosphate, and $5 \mu \mathrm{l}$ of DNA template. Distilled water was added to make it up to $50 \mu$ l. The reaction was overlaid with $50 \mu 1$ sterile mineral oil. One $\mu$ l of the first round amplified product was used as DNA template in the second round of amplification.

PCR for $P$ acnes was also carried out as described above except that the primer concentrations were $1 \mu \mathrm{M}$ instead of $0.36 \mu \mathrm{M}$ used for eubacterial amplification. The PCR was performed in a Perkin-Elmer (Cetus, USA) automatic thermocycler (model 480). The temperatures for denaturation, annealing, extension, and the number of cycles used were as described by Hykin et al..$^{10}$

\section{PCR specificity}

Both the universal eubacterial primers and $P$ acnes primers were tested for their specificity with DNA extracted from all the principal bacteria (Table1) known to cause endophthalmitis. Ten laboratory isolates, identified as $P$ acnes, were also tested for specificity with $P$ acnes primers.

\section{PCR sensitivity}

Tenfold serial dilutions of DNA extracted from Staphylococcus epidermidis in water were amplified with the universal primers $\mathrm{U} 1, \mathrm{rU} 4$ and $\mathrm{U} 2$, and rU3. Tenfold serial dilutions of DNA extracted from $P$ acnes were amplified with $P$ acnes primers $\mathrm{Pa} 1, \mathrm{rPa} 3$, and $\mathrm{Pa} 1, \mathrm{rPa} 2$. The sensitivity of each PCR procedure was assessed after one and two rounds. 
Table 2 Correlation of the results of conventional microbiological investigations and the PCR using universal eubacterial primers on 58 intraocular specimens from patients with clinical diagnosis of infective endophthalmitis and 20 intraocular specimens from non-infective disorders.

\begin{tabular}{|c|c|c|c|c|c|c|c|c|}
\hline \multirow{3}{*}{$\begin{array}{l}\text { Type of } \\
\text { endophthalmitis } \\
(n=58) \\
(38 \mathrm{VF}, 20 \mathrm{AH})\end{array}$} & \multicolumn{8}{|c|}{ Infective endophthalmitis } \\
\hline & \multicolumn{2}{|c|}{$\begin{array}{l}\text { Smeart, } \\
\text { culture+ } \\
12(12)\end{array}$} & \multicolumn{2}{|c|}{$\begin{array}{l}\text { Smeart, } \\
\text { culture- } \\
4(4)\end{array}$} & \multicolumn{2}{|c|}{$\begin{array}{l}\text { Smear-, } \\
\text { culturet } \\
4(4)\end{array}$} & \multicolumn{2}{|c|}{$\begin{array}{l}\text { Smear-, culture- } \\
38(17)\end{array}$} \\
\hline & $A H$ & $V F$ & $\overline{A H}$ & $V F$ & $\overline{A H}$ & $V F$ & $A H$ & $V F$ \\
\hline $\begin{array}{l}\text { Postoperative } \\
(\mathrm{n}=36)\end{array}$ & $4(4)$ & $4(4)$ & $2(2)$ & $1(1)$ & $2(2)$ & $2(2)$ & $8(6)$ & $13^{\star}(6)$ \\
\hline $\begin{array}{l}\text { Post-traumatic } \\
\quad(n=13) \\
\text { Endogenous }(n=9)\end{array}$ & - & $4(4)$ & - & $1(1)$ & - & - & $\begin{array}{l}2(0) \\
2^{\star}(0)\end{array}$ & $\begin{array}{l}6(4) \\
7^{\star}(1)\end{array}$ \\
\hline
\end{tabular}

$\mathrm{AH}=$ aqueous humour; $\mathrm{VF}=$ vitreous fluid.

$+=$ positive for bacteria; $-=$ negative for bacteria

Numbers in parentheses indicate PCR positivity.

Among 58 specimens, bacteriologically $20(34.5 \%)$ were positive and $38(65.5 \%)$ were negative.

$\star 6 \mathrm{VF}$ (three in the postoperative group and three in the endogenous group) and one $\mathrm{AH}$ (in the endogenous group) were positive for fungi but negative by PCR for eubacterial genome.

Among the 20 control specimens (six AH, $14 \mathrm{VF}$,) from non-infected cases, one was positive by PCR for eubacterial genome, and none by PCR for $P$ acnes genome.

Table 3 Results of PCR for detection of P acnes genome in 17 smear and culture negative but eubacterial genome positive specimens

\begin{tabular}{|c|c|c|c|c|}
\hline \multirow[b]{2}{*}{ Type of endophthalmitis $(n=17)$} & \multicolumn{2}{|c|}{ PCR positive $(n=9)$} & \multicolumn{2}{|c|}{ PCR negative $(n=8)$} \\
\hline & $A H$ & $V F$ & $A H$ & $V F$ \\
\hline Postoperative $(n=12)$ & 4 & 3 & 2 & 3 \\
\hline Post-traumatic $(n=4$ & - & 2 & - & 2 \\
\hline Endogenous $(\mathrm{n}=1)$ & - & - & - & 1 \\
\hline
\end{tabular}

$\mathrm{AH}=$ aqueous humour; $\mathrm{VF}=$ vitreous fluid.

PCR analysis of clinical specimens

Five $\mu$ l of DNA extracted from each clinical sample were added directly to the PCR reaction. Each clinical specimen was amplified in the presence of two negative controls-one for sample extraction and another as a reagent control and a positive control. The PCR products were separated by electrophoresis in $2 \%$ agarose gel containing ethidium bromide 0.5 $\mu \mathrm{g} / \mathrm{ml}$ and visualised on a ultraviolet transilluminator at $302 \mathrm{~nm}$ wave length (Pharmacia, Uppsala, Sweden).

\section{Results}

PCR SPECIFICITY

The universal primers $\mathrm{U} 1$ and $\mathrm{rU} 4$ (one round), U2 and rU3 (two round) amplified successfully DNA from all the bacterial strains tested to give a $766 \mathrm{bp}$ product after one round and a $470 \mathrm{bp}$ product after two rounds respectively. The $P$ acnes primers amplified DNA from all $P$ acnes isolates only to give a $387 \mathrm{bp}$ product after one round and a $160 \mathrm{bp}$ product after two rounds respectively.

\section{PCR SENSITIVITY}

Eubacterial primers

DNA amplification after the one round amplification permitted the detection of $1 \mathrm{pg}$ of $S$ epidermidis DNA. With nested PCR (at the end of two round amplification) $40 \mathrm{fg}$ of $S$ epidermidis DNA was detected.

\section{$P$ acnes primers}

DNA amplification after the one round permitted the detection of $1 \mathrm{pg}$ of $P$ acnes DNA, and $50 \mathrm{fg}$ of $P$ acnes DNA after two rounds.
Results of PCR and conventional microbiological investigations of clinical specimens

Among the 20 controls from non-infective cases, one $(5 \%)$ was positive by nested PCR with universal eubacterial primers and none with $P$ acnes primers. Hence, the specificity of PCR with eubacterial primers was $95 \%$ and $100 \%$ with $P$ acnes primers. The 58 specimens from patients with clinically evident infective endophthalmitis were divided into three groups based on clinical types of endophthalmitis and into four categories based on the results of conventional microbiological investigations (direct smears and cultures), as shown in Table 2 . The majority of the endophthalmitis cases $(36(62.1 \%))$ were in the postoperative group, followed by the post-traumatic (13 $(22.4 \%))$, and endogenous (nine (15.5\%)) groups. Among these 58 specimens 27 $(46.5 \%)$ were positive by culture, of which 20 $(34.5 \%)$ were positive for bacterial, seven $(12 \%)$ for fungal aetiology, and 31 (53.5\%) were microbiologically negative for infective aetiology by conventional methods (Table 2). Nested PCR for eubacterial genome showed positivity in $37(63.8 \%)$ specimens and showed $100 \%$ correlation with the first three categories of specimens which were bacteriologically positive. Thus, PCR could detect eubacterial genome in $17(44.7 \%)$ out of 38 bacteriologically negative specimens in the fourth category (Table 2), increasing the sensitivity from $46.5 \%$ to $75.8 \%$ for proving infectious aetiology in the specimens. The amplified products of some of the specimens are shown in Figure 1. Further PCR for $P$ acnes with the 17 eubacterial genome positive specimens revealed the presence of $P$ acnes specific genome in nine (52.9\%) specimens (Table 3), indicating $P$ acnes to be the possible causative agent of endophthalmitis in those cases. The amplified products for $P$ acnes at the end of two rounds of some of the specimens are indicated in Figure 2. The 21 PCR negative specimens included seven fungus positive specimens; in the rest of the 14 specimens negative by PCR and conventional microbiological techniques, infectious aetiology could not be determined. Thus, the sensitivity of detection of bacterial aetiology increased from $34.5 \%$ to $63.8 \%$ by inclusion of PCR.

The analysis of the results of PCR on bacteriologically negative $\mathrm{AH}$ and $\mathrm{VF}$ separately showed that six $(54.5 \%)$ of the $11 \mathrm{AH}$ and 11 (55\%) of the $20 \mathrm{VF}$ were positive for eubacterial genome. Among the eubacterial genome positive specimens in the smear negative culture negative group, four out of six $\mathrm{AH}$ $(66.66 \%)$ and five out of $11 \mathrm{VF}$ ( $45.45 \%)$ were positive for the $P$ acnes genome.

\section{Discussion}

In most recent studies approximately $75 \%$ of eyes with suspected endophthalmitis were culture positive from intraocular specimens. ${ }^{6}{ }^{16}$ Our data (unpublished) on microbiological investigations of infective endophthalmitis during a period of 5 years (1989-94) indicated that $43.8 \%$ of intraocular specimens only were microbiologically positive including fungal 


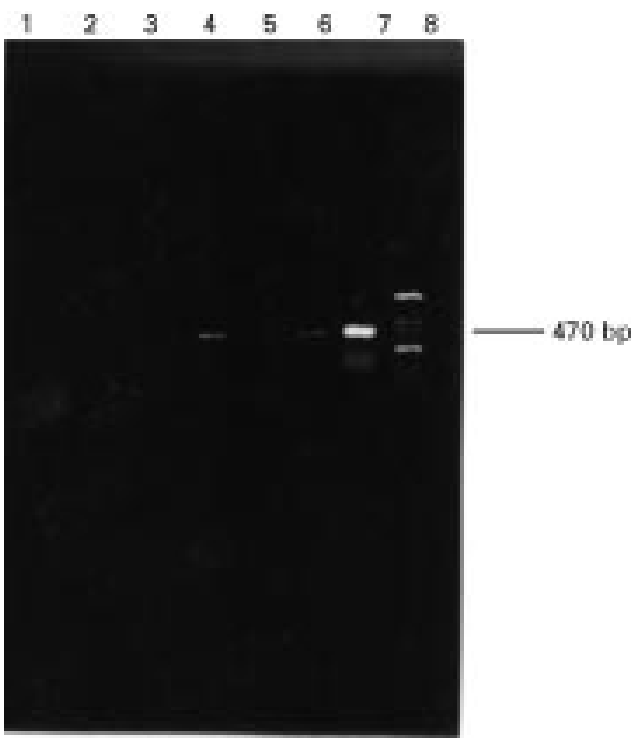

Figure 1 Nested PCR results with universal eubacterial primers U2,rU3. Lanes 1, negative control (reagents); 2, negative control (sample extraction); 3, $M^{\star} 1162 / 96$ (VF) negative; 4, M 1111/96 (AH) positive; 5, M 1537/96 (VF) negative; 6, M 59/96 (VF) positive; 7, positive control; 8, molecular weight marker (Phi X 174/Hinf 1 Digest). ${ }^{\star} M$ denotes the laboratory identification numbers.

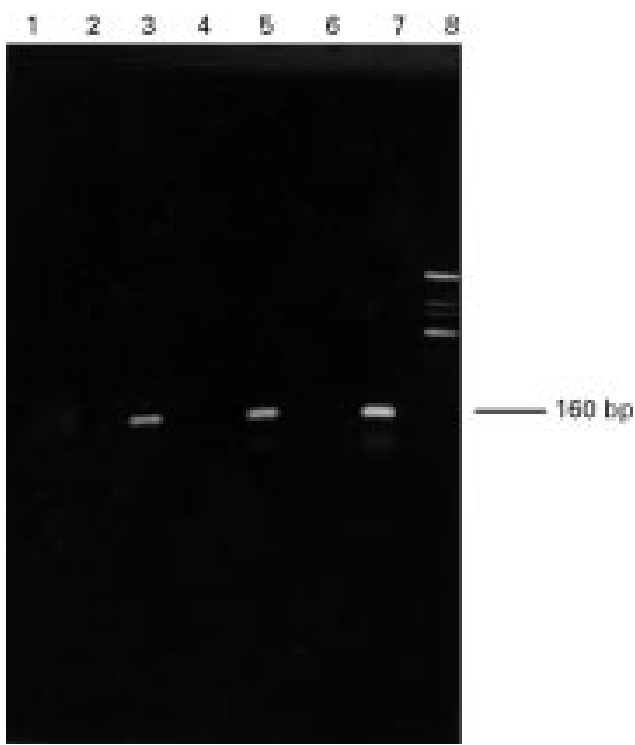

Figure 2 Nested PCR results with primers Pa1, rPa2. Lanes 1, negative control (reagents); 2, negative control (sample extraction); $3, M^{\star} 1189 / 96(A H)$ positive; $4, M$ $2512 / 95$ negative (VF); 5, M 59/96 (VF) positive; 6, $M$ 2964/96 (AH) negative; 7, positive control; 8, molecular weight marker (Phi X 174/Hinf 1 Digest). ${ }^{\star} M$ denote the laboratory identification numbers.

aetiology and in the present study period it was $46.5 \%$. The reason could be the prior antibiotic therapy, as most of our patients were referred to us after varying periods of treatment.

Postoperative endophthalmitis following cataract extraction is considered the most common form of endophthalmitis, accounting for approximately $70 \%$ of infectious endophthalmitis cases. ${ }^{17}$ In our study also, the majority $(62.1 \%)$ of the cases were from postoperative endophthalmitis and most $(58.3 \%)$ of them were negative for bacteria by conventional microbiological investigations. However, PCR could identify $17(54.8 \%)$ more cases with eubacterial genome, and $12(70.5 \%)$ of them were in the postoperative group underlining the significant role of bacteria as the common cause of endophthalmitis in this group. It is a known fact that $P$ acnes is a common causative agent in this group and our study also showed that the $P$ acnes genome was detected in more cases from the postoperative endophthalmitis group than from the other two groups. Thus, bacteriologically positive specimens increased by $29.3 \%$ by inclusion of PCR among the laboratory techniques used in this study.

Non-infective postoperative inflammation has been attributed to many different causes, like lens design, surgical manipulation, retained soft lens matter, toxic lens syndrome, and phacogenic uveitis. ${ }^{18}{ }^{19}$ In cases of posttraumatic endophthalmitis it is often difficult to differentiate the inflammation due to trauma from the superimposed infectious process and in such a situation the detection of the aetiology becomes imperative. Determination of whether a given case of endophthalmitis is infectious or sterile dictates the subsequent modification of therapy. The infective aetiology can be established only by demonstrating an infective agent in the intraocular specimen. In this study in spite of our best efforts $P$ acnes could not be isolated in culture from any one of the specimens. However, PCR was helpful in detecting the $P$ acnes genome in seven of the postoperative cases and two of the posttraumatic cases and thus was useful as a diagnostic test in $P$ acnes endophthalmitis.

Previous studies ${ }^{1620}$ have shown that the yield of cultures in endophthalmitis is greater from undiluted vitreous than from aqueous. Hence, it has been indicated that if infectious endophthalmitis is suspected clinically, it is essential to obtain a vitreous sample for culture. ${ }^{1}$ The reason cited is the ability of anterior chamber rather than the vitreous to eliminate infection. ${ }^{21}$ In our study, PCR on $\mathrm{AH}$ was equally sensitive to that on VF for detection of both the eubacterial genome and the $P$ acnes genome in microbiologically negative specimens. These findings are extremely significant, as the anterior chamber tap is a simpler and safer office procedure compared with diagnostic vitreous aspiration. Hence, the anterior chamber tap could be the method of choice in the diagnosis of endophthalmitis when a highly sensitive molecular technique such as PCR is applied.

PCR has the potential advantages in that only a small sample is required for analysis and minute numbers of bacteria could be detected. PCR based detection of the eubacterial genome has been developed based on the conserved regions of the $16 \mathrm{~S} \mathrm{rDNA} / \mathrm{rRNA}$ sequence of $E$ coli by several groups. ${ }^{22}{ }^{23}$ The small subunit of rRNA contains segments that are conserved at species, genus, and kingdom level. Universal primers chosen from $16 \mathrm{~S}$ rDNA have a large amount of sequence information and highly conserved regions of the gene which allows for synthesis of primers that amplify a wide variety of bacteria. The specificity and sensitivity of eubacterial and $P$ acnes 
primers used were very high and comparable with the previous study. ${ }^{10}$ In testing of the intraocular specimens PCR also showed 100\% correlation with smear and culture results. In addition, by PCR bacterial infection could be attributed to $54.8 \%$ of bacteriologically negative specimens. In the study by Hykin et $a l,{ }^{10}$ of 29 control vitreous samples, four were found to be positive for eubacterial genome by PCR. A similar positive result was found in one of the $20(5 \%)$ control samples we tested. The false positive rate $(5 \%)$ was much lower than in the previous study. As suggested by them, we also believe that it could be due to contamination with conjunctival ocular flora during collection of the specimen.

Further studies are needed to identify the specific eubacterial strains in the specimens positive for eubacterial genome, but negative for $P$ acnes genome. Our study has clearly demonstrated that PCR on intraocular specimens, particularly in $\mathrm{AH}$, is of great value as a diagnostic test and can be used as an alternative in bacteriologically negative specimens by conventional methods.

1 Puliafito CA, Baker AS, Haaf J, et al. Infectious endophthalmitis - review of 36 cases. Ophthalmology 1982;89:921-9.

2 Cowen CL, Maddin WM, Hatem GF, et al. Endogenous Bacillus cereus endophthalmitis. Ann Ophthalmol 1982;19: 65-8.

3 Ormerod LD, Paton BG, Haff J, et al. Anaerobic bacterial endophthalmitis. Ophthalmology 1982;94:799-808.

4 Roussel TJ, Olson ER, Rice T, et al. Chronic post-operative endophthalmitis associated with Actinomyces species. Arch Ophthalmol 1982;109:60-2.

5 Forster RK. Endophthalmitis-diagnostic cultures and visual results. Arch Ophthalmol 1974;92:387-92.

6 Rowsey JJ, Newson DL, Sexton DJ, et al. Endophthalmitiscurrent approaches. Ophthalmology 1982;89:1055-66.
7 Burstain JM, Grimprel E, Lukehart SA, et al. Sensitive detection of Treponema pallidum by using polymerase

8 Skov Jensen J, Uldum SA, Sondergard AJ, et al. Polymerase chain reaction for detection of Mycoplasma genitalium in clinical samples. F Clin Microbiol 1991; 29:46-50.

9 Forbes BA, Hicks KES. Direct detection of Mycobacterium tuberculosis in respiratory specimens in a clinical laboratory by polymerase chain reaction. If Clin Microbiol tory by polymerase

10 Hykin PG, Tobal K, McIntyre G, et al. The diagnosis of delayed post-operative endophthalmitis by polymerase chain reaction of bacterial DNA in vitreous samples. $f \mathrm{Med}$ Microbiol 1994;40:408-15.

11 Meisler DM, Mandelbaum S. Propionibacterium acnes endophthalmitis after ECCE-review of reported cases. Ophthalmology 1991;96:54-61.

12 Vafidis GC. Propionibacterium acnes endophthalmitis. (Editorial) Br f Ophthalmol 1991;75:706.

13 Allen SD. Anaerobic bacteria. In: Lennete Edwin H, ed. Manual of clinical microbiology. 4th ed. Washington DC: American Society for Microbiology, 1985:413-72.

14 Baron EJ, Peterson LR, Finegold SM. Bailey and Scott's diagnostic microbiology, 9th ed. St Louis: Mosby, 1994:79136.

15 Collee JG, Miles RS, Watt B. Tests for identification of bacteria. In: Collee JG, Fraser AG, Marmion BP, et al. Practical medical microbiology. 14th ed. Edinburgh: Churchill Livingstone, 1996:131-50.

16 Bohigian GM, Olk RJ. Factors associated with a poor visual result in endophthalmitis. Am f Ophthalmol 1986;101:332-

17 Forster RK, Abbott RL, Gelender H. Management of infectious endophthalmitis. Ophthalmology 1980; 87:313.

18 Apple DJ, Mamalis N, Loftfield K, et al. Complications of intraocular lenses - a historical and histopathological review. Surv Ophthalmol 1984;29:1-54.

19 Meltzer DW. Sterile hypopyon after intraocular surgery. Arch Ophthalmol 1980;98:100-4.

20 Barza M, Pavan PR, Doft BH, et al. Evaluation of microbiological diagnostic techniques in postoperative endophthalmitis in the Endophthalmitis Vitrectomy Study. Arch Ophthalmol 1997;115:1142-50.

21 Maylath FR, Leopold IH. Study of experimental intraocular infection. Am f Ophthalmol 1955;40:86-101

22 Weisburg WG, Barnes SM, Pelletier DA, et al. 16S ribosomal DNA amplification for phylogenetic study. $\mathcal{f}$ Bacteriol 1991;173:697-703.

23 Chen. K, Neimark H, Rumore P, et al. Broad range DNA probes for detecting and amplifying eubacterial nucleic acids. FEMS Microbiol Lett 1989;57:19-24. 